\title{
Comparison Study Between Laparoscopic Radical Prostatectomy versus Robotic Radical Prostatectomy in Patient with TUR-P History
}

\author{
Moammar Andar Roemare Siregar, Chaidir Arif Mochtar, Rainy Umbas, Agus Rizal AH Hamid
}

Department of Urology, Dr. Cipto Mangunkusumo National General Hospital, Faculty of Medicine, Universitas Indonesia, Jakarta, Indonesia

\section{ARTICLE INFO}

Received : 16 June 2019

Reviewed : 10 July 2019

Accepted : 20 November 2019

\section{Keywords:}

transurethral resection of prostate, radical prostatectomy, prostate cancer

\author{
*Corresponding author: \\ Agus Rizal AH Hamid \\ Department of Urology, Dr. Cipto \\ Mangunkusumo National General \\ Hospital, Faculty of Medicine, \\ Universitas Indonesia, Jakarta, Indonesia \\ rizalhamid.urology@gmail.com
}

\begin{abstract}
Background: The number of men with benign prostate hyperplasia undergoing transurethral resection of prostate (TURP) with the subsequent development of prostate cancer has been increasing. This study aimed to compare the surgical, oncological, and functional outcomes of robotic and laparoscopic radical prostatectomy techniques in patients with the history of
\end{abstract} TURP.

Methods: Literature search of electronic databases was performed through Pubmed, Science Direct, SCOPUS, and CENTRAL databases. Cochrane Risk of Bias Tool was then employed to assess the risk of bias in each study. Grey literature was also searched from sources such as Cancer Care Ontario and conference abstracts. Critical appraisals of included studies were conducted using the Newcastle-Ottawa Scale.

Results: The searches located 1258 citations, but only 11 studies were included in the final selection. Most studies had a good methodological quality based on the Ottawa Scale. The mean age of samples was varied among each study from 61.8 to 70.8 years. The TURP history significantly affects biochemical recurrences (OR 2.29, 95\% Cl 1.14-4.59), intraoperative blood loss (MD $57 \mathrm{ml}$; 95\% Cl 6-108 m), prolonged operative duration (MD 20 minutes; 95\% Cl 3-37 minutes), and surgical complications (OR $2.54,95 \% \mathrm{Cl} 1.79-3.60$ ) following radical prostatectomy for prostate cancer. In the subgroup analysis, only prolonged operative duration and surgical complications were significant both in laparoscopic and robotic radical prostatectomy. There was no association between the TURP history and the positive surgical margin rate in total and subgroup analyses.

Conclusions: The previous TURP history affects the outcomes of patients who underwent radical prostatectomy, either laparoscopic or robotic.

\section{INTRODUCTION}

Prostate cancer is a major health concern among elderly males ( $>70$ years of age) in most developed countries [1]. According to GLOBOCAN 2012, prostate cancer ranked just below lung cancer in terms of the highest incidence in males and fourth-highest incidence for both sexes [2]. To eradicate the affected malignant tissue, radical prostatectomy (RP) is often performed. The procedure is employed by removing prostate gland entirely, resecting both seminal vesicles, and removing sufficient tissue area until negative margins are reached. Pelvic lymph node could also be resected bilaterally when RP is performed to prevent cancer reaching those structures. An ideal RP should eradicate the disease without disturbing patient's continence [3].
$\mathrm{RP}$ represents the gold standard in the management of localized prostate cancer and could be performed with several techniques such as retropubic incision, perineal incision, laparoscopic, and robotic-assisted techniques. Due to the nature of the disease, RP procedure will always be benefitting most to patients with localized prostate cancer whose result may diminish when the tumor has advanced beyond the prostate glands or metastasize has occurred. Urologists should ensure complete excision of the malignant lesion to prevent the risk of recurrence [4].

The number of RP procedures performed electively to treat primary localized, incidental/subsequent localized prostate cancer for individuals with the history of surgical treatments for obstructive benign disease has been increasing [5]. This finding is expected as more 
men with clinically localized prostate cancer had undergone transurethral resection of prostate (TURP) for benign prostatic enlargement in the past. Consistently, the increasing incidence of BPH and prostate cancer with age further supports this data [6]. Several studies suggest that compared to patients who were previously treated with TURP, patients without any history of TURP procedure has statistically difference margin of localization [3]. Another study suggests that a patient with a history of undergoing TURP procedure might have less satisfactory outcomes regarding operative time, length of stay (LOS), positive margin rate (PMR) and complication rate [7].

Another study suggested that men with a history of pelvic or prostate surgeries have poorer outcomes than those without the history of such surgeries [8]. As being compliant to international guidelines, there is an increase in the number of institutions employing Laparoscopic radical prostatectomy (LRP) in the management of localized prostate cancer $[9,10]$. Several studies have been trying to determine continence and cancer control outcomes between LPR and open procedure but failed to show any significant difference [9]. We found that many studies have been conducted to evaluate the effect of previous TURP on laparoscopic radical prostatectomy (LRP). However, there has not been any systematic review or meta-analysis done regarding this topic. Therefore, this study is aimed at determining the effect of the previous TURP on the surgical, oncological, and functional outcomes of patients who undergo robotic and laparoscopic radical prostatectomy.

\section{METHODS}

\section{Evidence Acquisition}

Based on the Preferred Reporting Items for Systematic reviews and Meta-Analyses guidelines and the Quality of Reporting of Meta-analyses of Randomized Controlled Trials statement, we developed study criteria, eligibility criteria, literature searching and study selection, data extraction, quality assessment, and methods of statistical analysis.

Table 1. Distribution of cervical cancer patients

\begin{tabular}{ll}
\hline Patients & $\begin{array}{l}\text { Prostate cancer patients underwent } \\
\text { radical prostatectomy }\end{array}$ \\
\hline Interventions & Patient with history of TURP \\
\hline Comparisons & Patient without history of TURP \\
\hline Outcome & $\begin{array}{l}\text { Positive surgical margin, Intraoperative } \\
\text { blood loss, Operative duration, Surgical } \\
\text { complication, Biochemical recurrence }\end{array}$ \\
\hline
\end{tabular}

\section{Eligibility Criteria}

We included both patients with and without TUR-P history. The study subjects must have undergone radical prostatectomy procedures, either laparoscopic or robotic. Study designs could be interventional studies, prospective observational studies, or retrospective studies and standardized patients with any history of TUR-P and without TUR-P. We included studies with positive surgical margin, intraoperative blood loss, operative duration, surgical complication, and biochemical recurrence as the outcomes. Only articles written in English with full-text article available are included and non-systematic review articles are excluded.

\section{Literature Search and Study Selection}

We conducted a literature search using Pubmed, Science Direct, SCOPUS and Cochrane Central Register of Controlled Trials (CENTRAL) in October 2016 with "transurethral" and "radical prostatectomy" as search terms. We conducted a secondary search of the grey literature (unpublished) from sources such as Cancer Care Ontario and conference abstracts. We also searched the reference lists of included articles. We only included studies comparing men who underwent radical prostatectomy with history of TURP and without history of TURP. However, we excluded non-English studies, non-systematically review studies, and animal studies.

\section{Study Selection and Data Extraction}

Duplicates are screened using EndNote X6 software and subsequently removed. Titles and abstracts are screened using predetermined inclusion and exclusion criteria mentioned above. All studies that fulfilled the inclusion and exclusion criteria underwent full-text review. For every eligible full text, we extracted the following data, patients with the history of TURP and without TURP who experienced Radical Prostatectomy (Laparoscopic or Robotic). All eligible full texts were reviewed by all authors separately using predetermined criteria (The Newcastle-Ottawa Scale). The reviewers assessed the bias component of each study separately. Biases assessed by the authors were selection bias, performance bias, detection bias, attrition bias, reporting bias, and other biases. The authors discussed their results after each author had finished the assessment individually. The disagreement was discussed among authors until the agreement was achieved or third party's opinion was consulted. For the outcomes, we extracted the result data as follows: positive surgical margin, intraoperative blood loss, operative duration, Surgical complication, biochemical recurrence. 


\section{Assessment of Bias and Statistical Method}

The Newcastle-Ottawa Scale (NOS) was used for assessing the quality of non-randomized studies in this meta-analysis with no quasi-experimental studies included. The Newcastle-Ottawa Scale evaluates three different domains of study quality: selection (4 items), comparability ( 1 item), and outcome for cohort studies (exposure for case-control studies, 3 items). A star was given for each fulfilled domain criterion, except for the comparability domain. The total number of stars given can be used to score the overall quality with a maximum of 9 stars. The quantitative synthesis of selected studies was analyzed with Review Manager (RevMan) 5.2 software and mean difference was obtained to measure the overall effect. Chi-square was employed to determine studies homogeneity whose result affects the metaanalysis model (fixed effect for $p>0.05$ and a random effect for $p<0.05$ ) being used.

\section{RESULTS}

\section{Literature search and characteristics of eligible studies}

The searches located 1258 citations. Of these, 798 citations were in Pubmed, 282 citations in Science Direct, 120 citations in SCOPUS, and 25 citations in CENTRAL. The total grey literature found were 33 citations. All 494 duplicates were removed, leaving 764 citations to screen. After applying inclusion and exclusion criteria, the final analysis included 11 studies (Figure 1).

\section{The methodological quality of the included studies}

The basic characteristics of the included studies and the results of critical appraisal using NOS criteria can be seen in Table 2 . Based on NOS scale, most of those studies were of high quality. Only 3 studies did not show acceptable comparability between groups in the cohort and only 4 studies did not follow up the cohort adequately.

\section{Positive surgical margin}

Results of total data processing for positive surgical margin outcomes found that of a total of 5065 patients, 4598 (90.7\%) were control patients (not underwent TURP) and 467 (9.3\%) experimental patients (who underwent TURP). Of the total 5065 patients, 1382 (27.2\%) patients experienced events compared with laparoscopic and robotic measures of 1264 in control patients, and 118 in experimental patients with $p=0.16$ (not significant). Meta-analysis of 11 studies found no significant difference in positive surgical margin between patients with history of TURP and without history of TURP (OR=1.19; 95\% $\mathrm{Cl}$ 0.93-1.53). In the sub-group analysis, no difference was found in laparoscopic and robotic subgroup analyses (Figure 2).

\section{Biochemical recurrence}

The analyses of 3 studies for biochemical recurrence outcomes show significantly higher biochemical recurrence in TURP compared to non-TURP group (OR $2.29,95 \% \mathrm{Cl}$ 1.14-4.59). No significant heterogeneity was shown in this pooled outcome (Figure 5).

\section{Intraoperative blood loss}

The pooled effect using random effect shows significant differences of intraoperative blood loss with TURP vs non-TURP group (MD $57 \mathrm{ml}$; Cl 95\% 6-108 $\mathrm{ml} ; \mathrm{p}=0.03$ ). However, in the subgroup analysis, the differences in blood loss between TURP and non-TURP group was non-significant either in laparoscopy or robotic RP groups.

\section{Operative duration}

The pooled effect of laparoscopic RP in the patient with the history of TURP showed significantly prolonged operative duration compared to non-TURP group (MD 20 minutes; $95 \% \mathrm{Cl} \quad 3-37$ minutes). This result was also found in the robotic group, longer duration of operation in the patient with the history of TURP (MD 17 minutes; 95\% Cl 4-31 minutes).

\section{Surgical complication}

Meta-analyses from 7 studies show higher complication rates in patients with a history of TURP compared to non-TURP. Complications assessed here were minor complications (Clavien I-II), anastomosis leakage, urinary infection, major complications (Clavien III-IV), rectal injury, and anastomotic stricture. This result was also found when the subgroup analysis was performed. The surgical complication was higher when RP was performed either with laparoscopy or robotic techniques. 


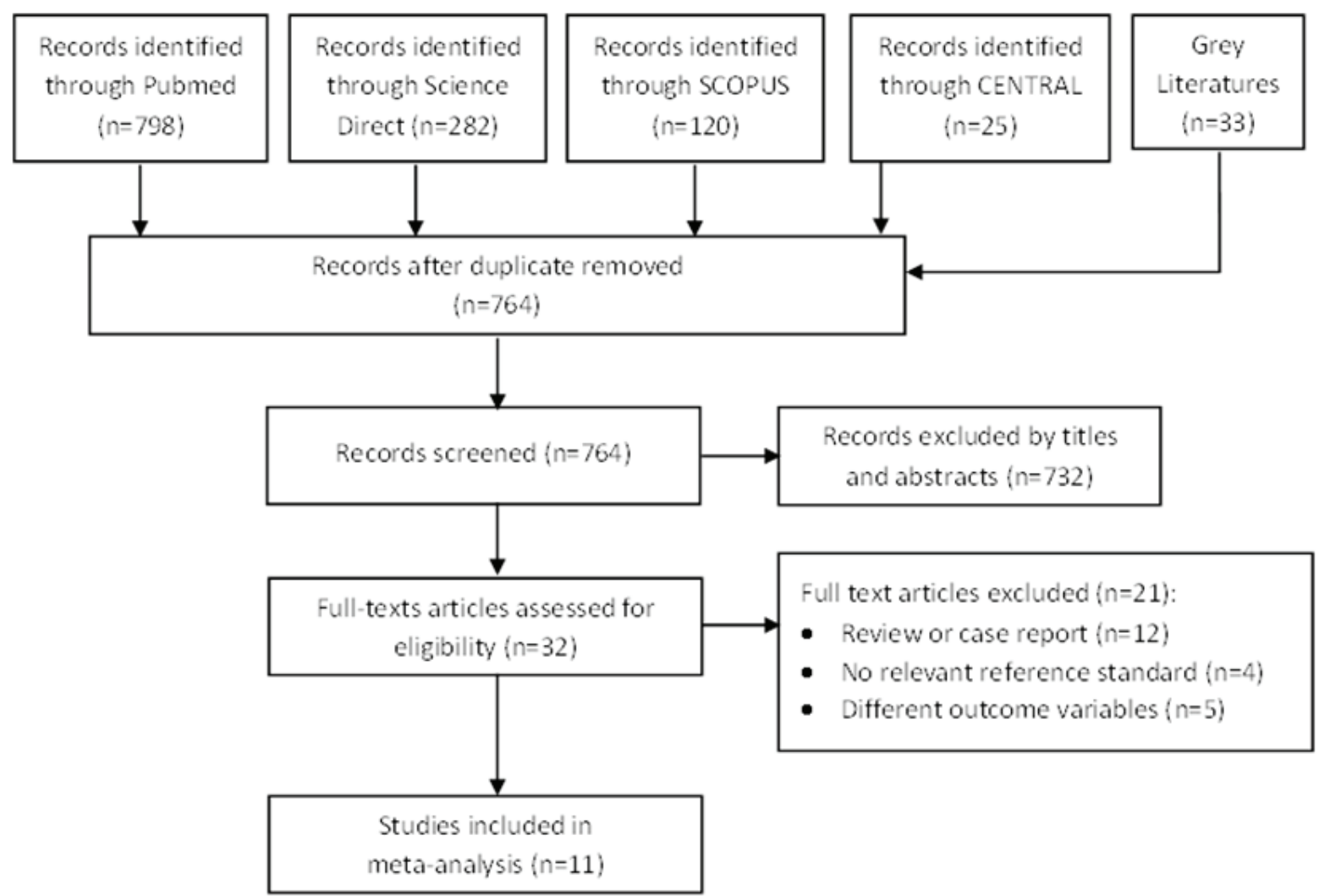

Figure 1. Search strategies flow chart

Table 2. Characteristics of included studies and the results of critical appraisal

\begin{tabular}{|c|c|c|c|c|c|c|c|c|c|}
\hline \multirow[b]{2}{*}{ No } & \multirow{2}{*}{$\begin{array}{l}\text { Study, First Name, } \\
\text { Year }\end{array}$} & \multirow{2}{*}{$\begin{array}{l}\text { No. of patients } \\
\text { (TURP vs } \\
\text { non TURP) }\end{array}$} & \multirow{2}{*}{$\begin{array}{l}\text { Mean Age } \\
\text { (years) }\end{array}$} & \multicolumn{3}{|c|}{ Clinical Stage (\%) } & \multicolumn{3}{|c|}{ Study Quality (Newcastle-Ottawa Scale) } \\
\hline & & & & T1 & $\mathrm{T} 2$ & T3 & $\begin{array}{l}\text { Selection } \\
\left(\operatorname{Max}^{* * * *}\right)\end{array}$ & $\begin{array}{c}\text { Comparability } \\
\left(\operatorname{Max}{ }^{* *}\right)\end{array}$ & $\begin{array}{l}\text { Outcome } \\
(\operatorname{Max} * * *)\end{array}$ \\
\hline 1 & Eden, 2007 [11] & TURP: 42 & $64.6 \pm 5.7$ & $67 \%$ & $33 \%$ & $0 \%$ & $* * * *$ & * & $* *$ \\
\hline 2 & Gacci, 2013 [12] & $\begin{array}{l}\text { TURP: } 75 \\
\text { Non TURP: } 2.333\end{array}$ & $65.3 \pm 6.5$ & $52 \%$ & $44 \%$ & $4 \%$ & $* * * *$ & $* *$ & $* * *$ \\
\hline 3 & Gupta, 2011 [6] & $\begin{array}{l}\text { TURP: } 26 \\
\text { Non TURP: } 132\end{array}$ & $\begin{array}{l}64.7(54-76) \\
63.4(50-76)\end{array}$ & $\begin{array}{l}0 \% \\
0 \%\end{array}$ & $\begin{array}{l}89 \% \\
77 \%\end{array}$ & $\begin{array}{l}11 \% \\
23 \%\end{array}$ & $* * * *$ & $* *$ & $* * *$ \\
\hline 4 & $\begin{array}{l}\text { Hampton, } 2008 \\
{[13]}\end{array}$ & $\begin{array}{l}\text { TURP: } 51 \\
\text { Non TURP: } 102\end{array}$ & N/A & $\begin{array}{l}78 \% \\
77 \%\end{array}$ & $\begin{array}{l}20 \% \\
23 \%\end{array}$ & $\begin{array}{l}2 \% \\
0 \%\end{array}$ & $* * * *$ & $* *$ & $* *$ \\
\hline 5 & Hung, 2014 [14] & $\begin{array}{l}\text { TURP: } 16 \\
\text { Non TURP: } 184\end{array}$ & $\begin{array}{l}67.5 \pm 7.4 \\
64.8 \pm 6.9\end{array}$ & $\begin{array}{l}50 \% \\
39 \%\end{array}$ & $\begin{array}{l}50 \% \\
55 \%\end{array}$ & $\begin{array}{l}0 \% \\
6 \%\end{array}$ & $* * * *$ & * & $* * *$ \\
\hline 6 & Jaffe, 2007 [15] & $\begin{array}{l}\text { TURP: } 119 \\
\text { Non TURP: } 119\end{array}$ & $\begin{array}{l}66.2 \pm 5.6 \\
60.7 \pm 7.0\end{array}$ & $\begin{array}{l}82 \% \\
68 \%\end{array}$ & $\begin{array}{l}5 \% \\
29 \%\end{array}$ & $\begin{array}{l}3 \% \\
3 \%\end{array}$ & $* * * *$ & $* *$ & $* *$ \\
\hline 7 & $\begin{array}{l}\text { Leewansangtong, } \\
2006 \text { [16] }\end{array}$ & $\begin{array}{l}\text { TURP: } 8 \\
\text { Non TURP: } 19\end{array}$ & $\begin{array}{l}70.8(66-76) \\
63.0(47-72)\end{array}$ & $\mathrm{N} / \mathrm{A}$ & N/A & N/A & $* * * *$ & $* *$ & $* * *$ \\
\hline 8 & Martin, 2009 [17] & $\begin{array}{l}\text { TURP: } 24 \\
\text { Non TURP: } 486\end{array}$ & $\begin{array}{l}70 \\
65\end{array}$ & $\mathrm{~N} / \mathrm{A}$ & $\begin{array}{l}58 \% \\
74 \%\end{array}$ & $\begin{array}{l}42 \% \\
26 \%\end{array}$ & $* * * *$ & * & $* * *$ \\
\hline 9 & Menard, 2008 [18] & $\begin{array}{l}\text { TURP: } 46 \\
\text { Non TURP: } 594\end{array}$ & $\begin{array}{l}66.7 \pm 4.9 \\
62.8 \pm 6.7\end{array}$ & $\begin{array}{l}0 \% \\
1 \%\end{array}$ & $\begin{array}{l}85 \% \\
57 \%\end{array}$ & $\begin{array}{l}15 \% \\
42 \%\end{array}$ & $* * * *$ & $* *$ & $* * *$ \\
\hline 10 & Tugcu, 2015 [19] & $\begin{array}{l}\text { TURP: } 25 \\
\text { Non TURP: } 36\end{array}$ & $\begin{array}{l}63.2 \pm 3.79 \\
62.97 \pm 3.65\end{array}$ & $\begin{array}{l}100 \% \\
100 \%\end{array}$ & $\mathrm{~N} / \mathrm{A}$ & N/A & $* * * *$ & $* *$ & $* *$ \\
\hline 11 & Yang, 2015 [20] & $\begin{array}{l}\text { TURP: } 35 \\
\text { Non TURP: } 35\end{array}$ & $\begin{array}{l}69.9(54-82) \\
68.9(51-76)\end{array}$ & $\begin{array}{l}100 \% \\
54 \%\end{array}$ & $\begin{array}{l}0 \% \\
46 \%\end{array}$ & N/A & $* * * *$ & $* *$ & $* * *$ \\
\hline
\end{tabular}




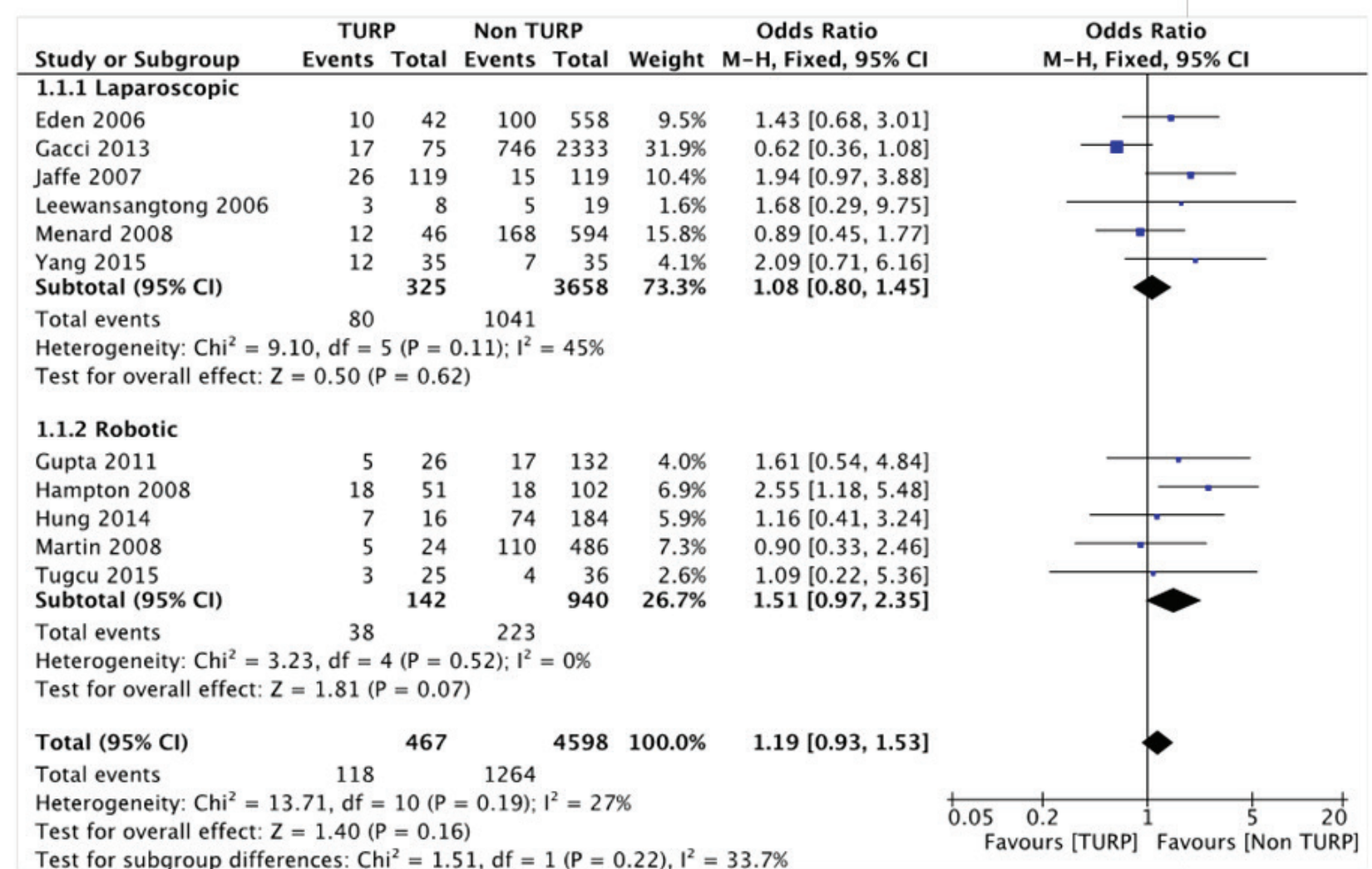

Figure 2. Forest plot of the effect of previous TURP with positive surgical margin

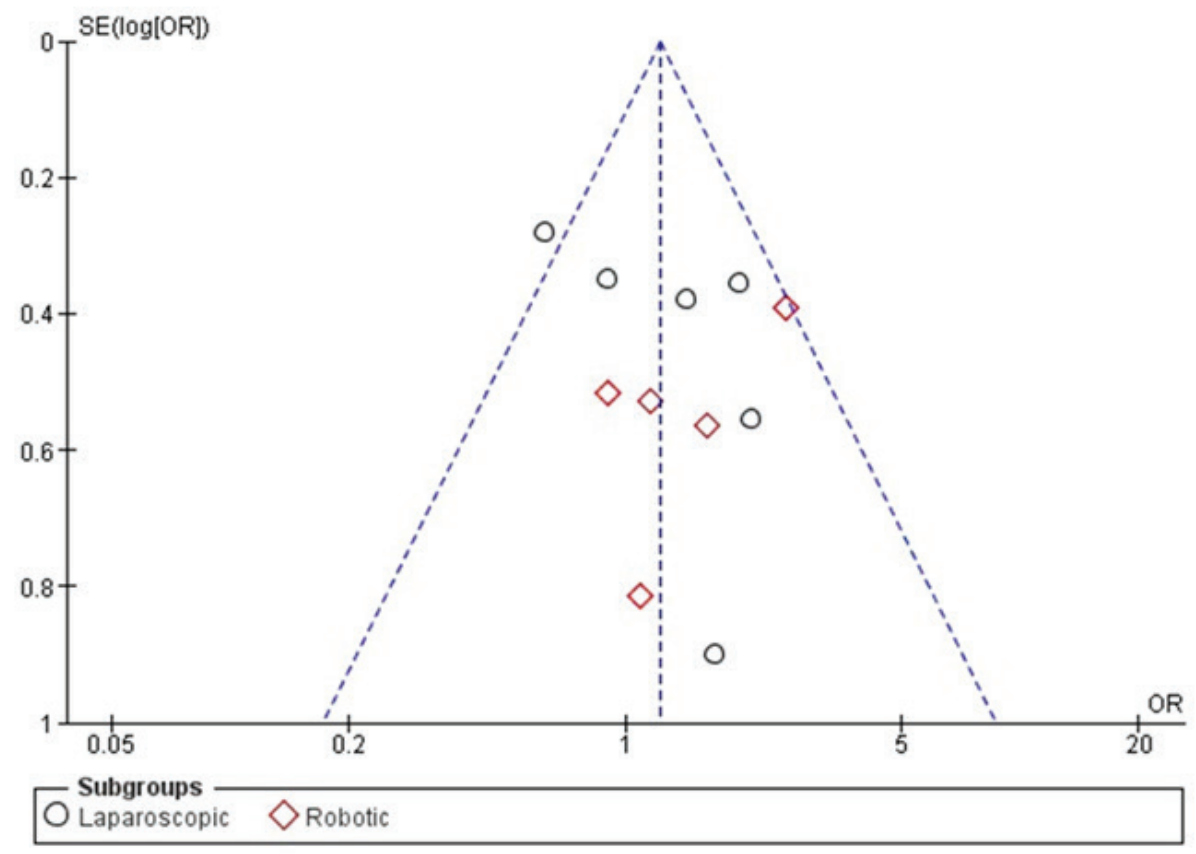

Figure 3. Funnel plot of the effect of the previous TURP with positive surgical margin 


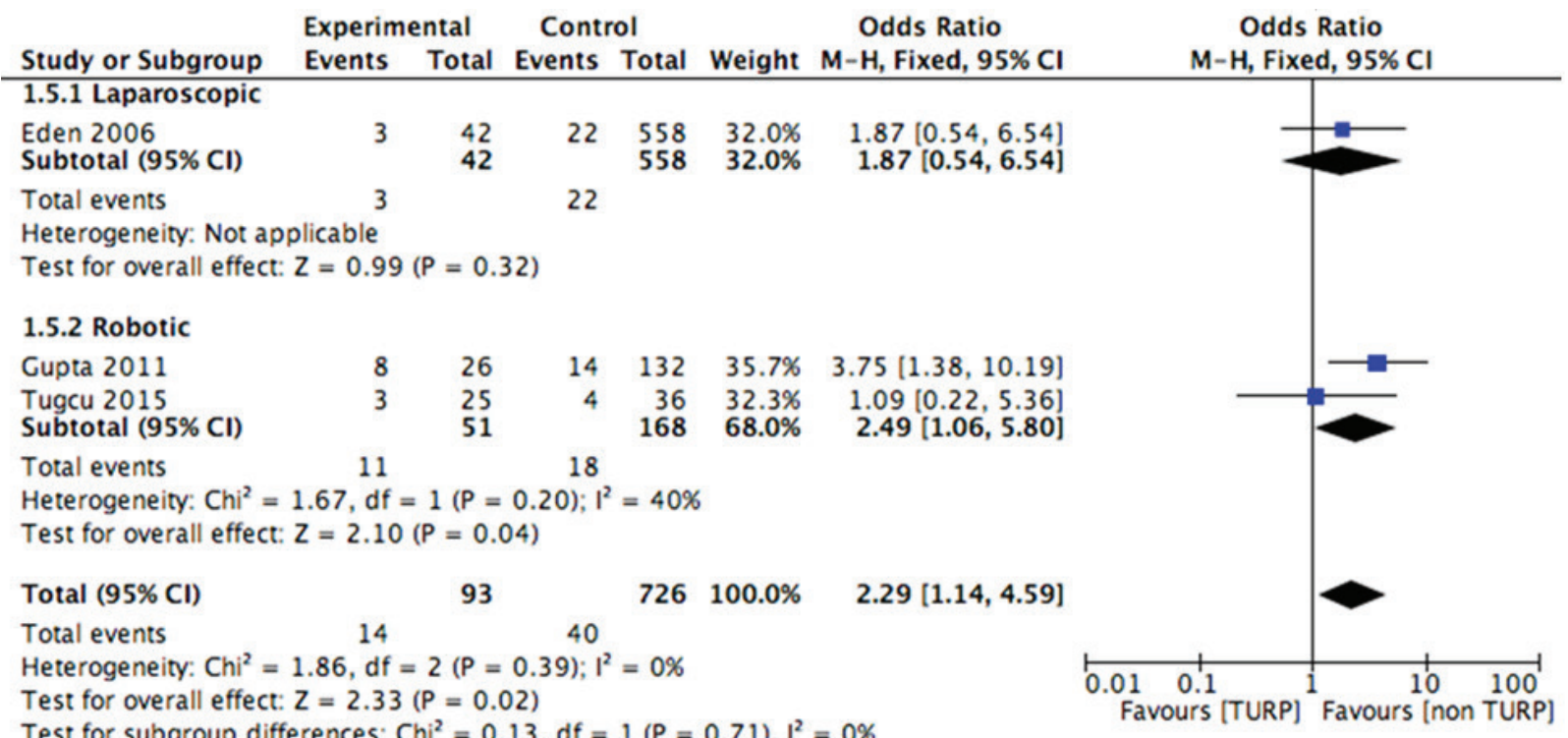

Figure 4. Forest plot of the effect of the previous TURP with biochemical recurrence

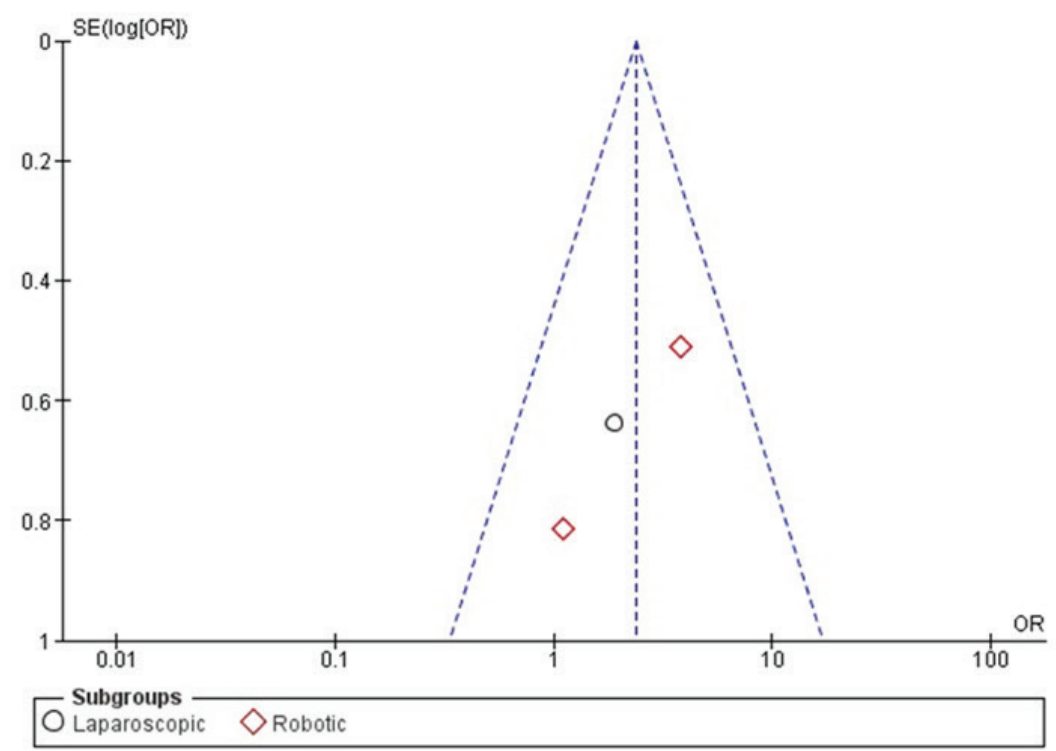

Figure 5. Funnel plot of the effect of the previous TURP with biochemical recurrence

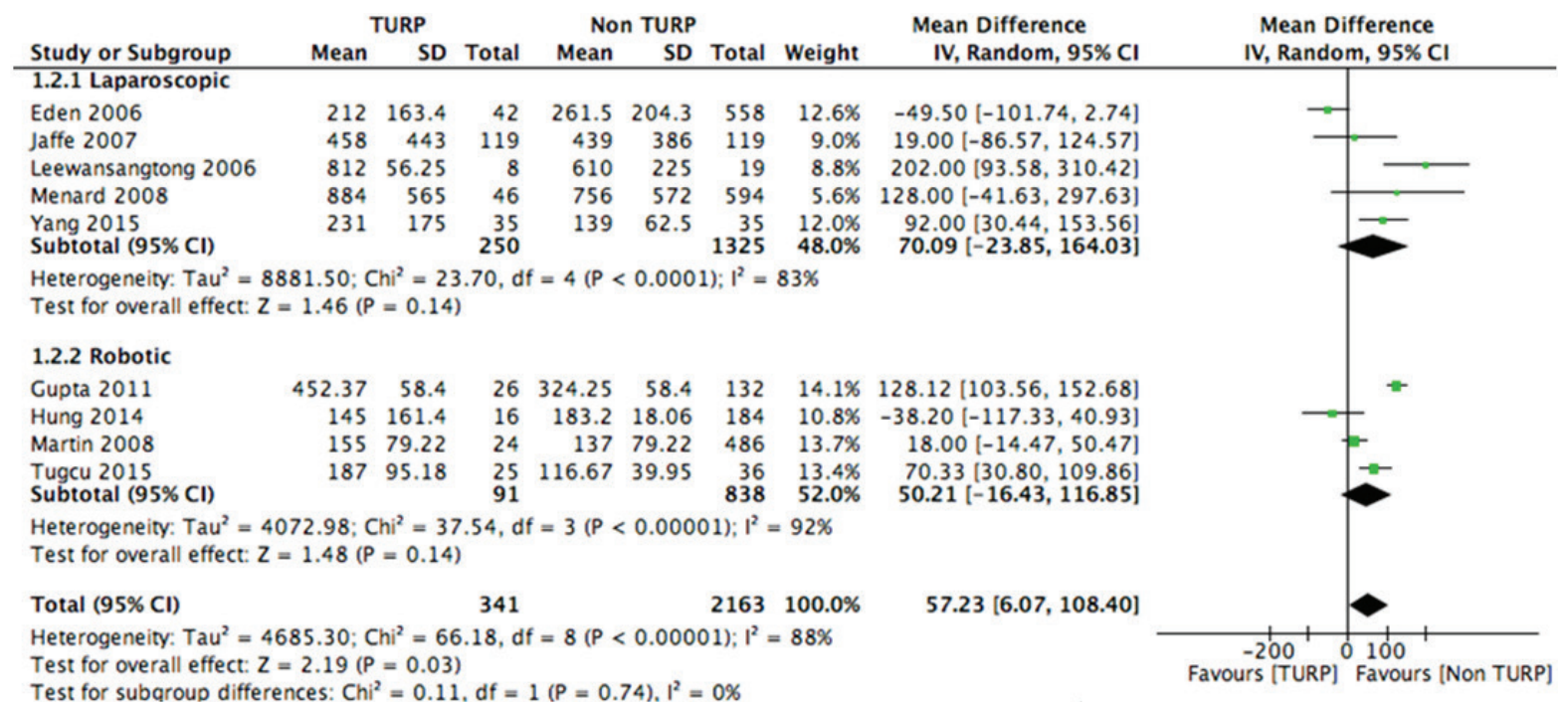

Figure 6. Forest plot of the effect of previous TURP with intraoperative blood loss 


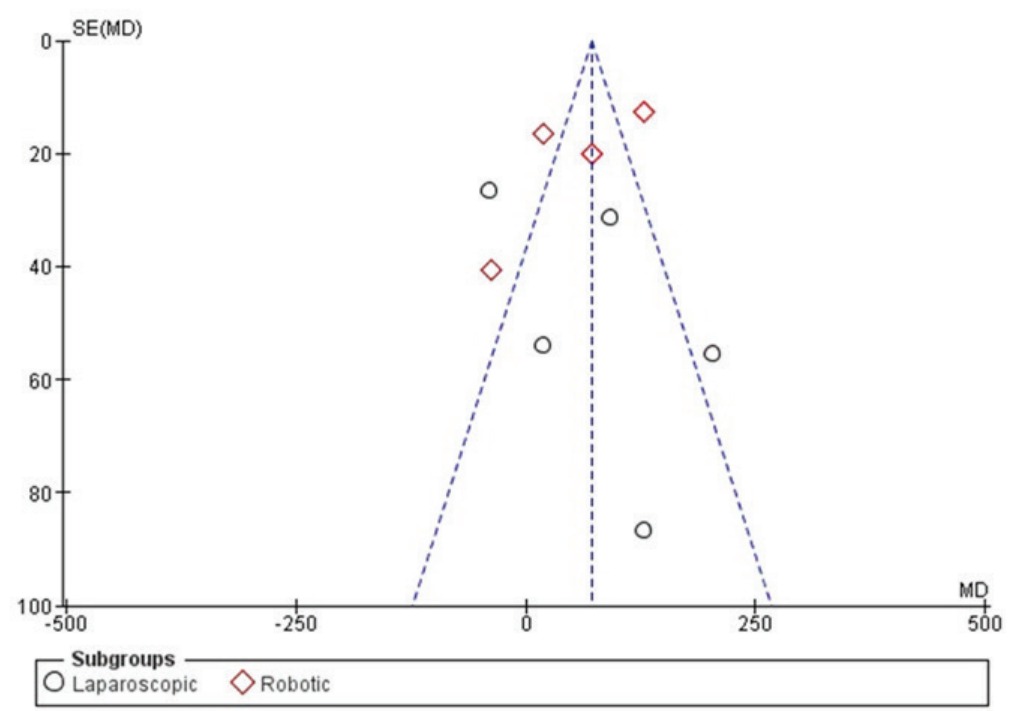

Figure 7. Funnel plot of the effect of the previous TURP with intraoperative blood loss

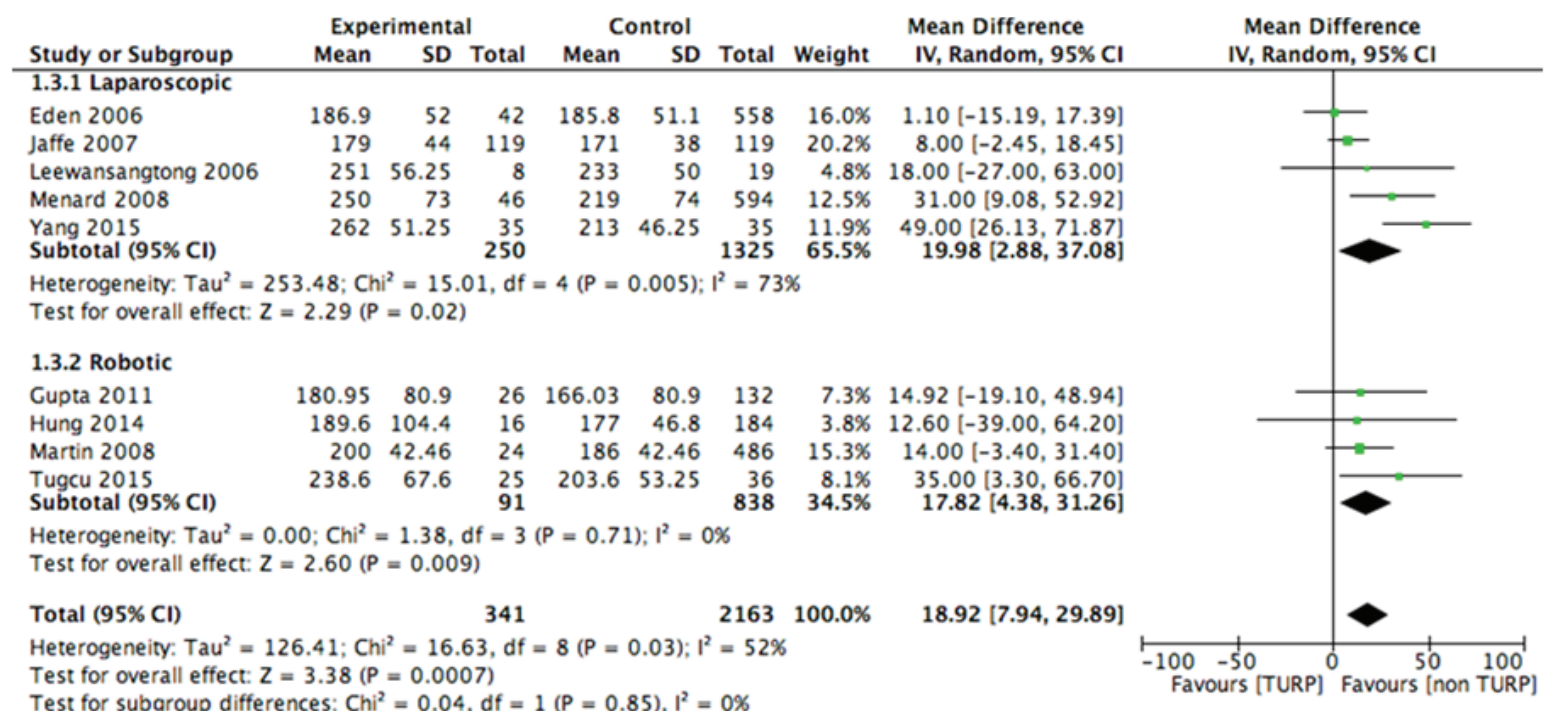

Figure 8. Forest plot of the effect of the previous TURP with operative duration

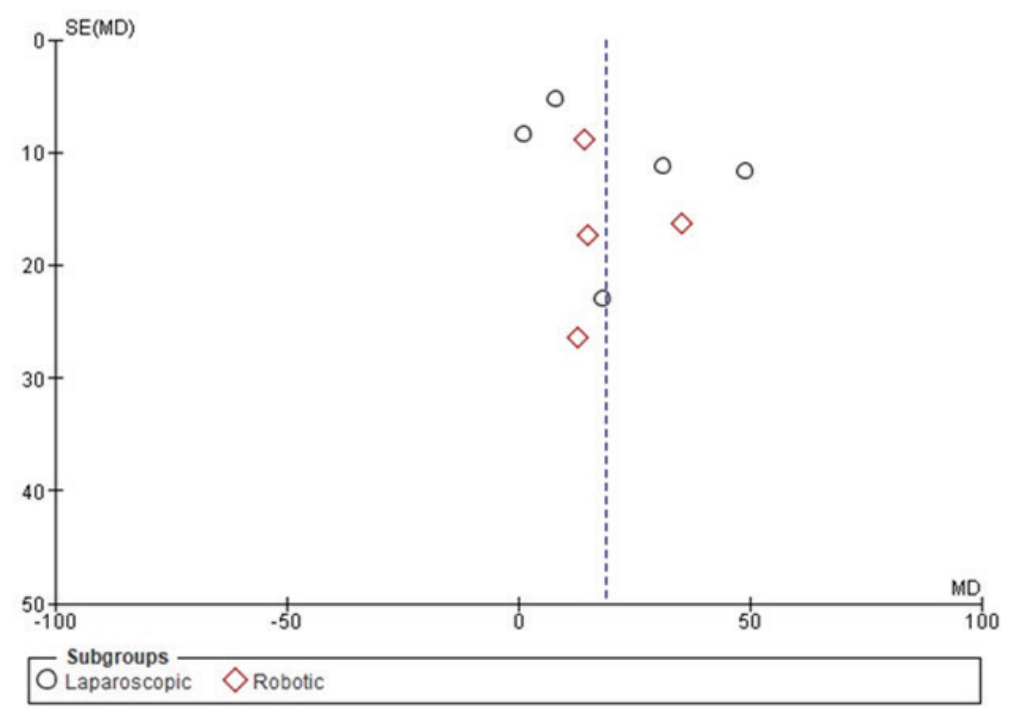

Figure 9. Funnel plot of the effect of the previous TURP with operative duration 


\begin{tabular}{|c|c|c|c|c|c|c|c|c|}
\hline \multirow{2}{*}{$\frac{\text { Study or Subgroup }}{1.4 .1 \text { Laparoscopic }}$} & \multicolumn{2}{|c|}{ Experimental } & \multicolumn{2}{|c|}{ Control } & \multirow[t]{2}{*}{ Weight } & \multirow[t]{2}{*}{$\begin{array}{l}\text { Odds Ratio } \\
\text { M-H, Fixed, } 95 \% \mathrm{CI}\end{array}$} & \multicolumn{2}{|c|}{$\begin{array}{c}\text { Odds Ratio } \\
\text { M-H, Fixed, } 95 \% \mathrm{Cl}\end{array}$} \\
\hline & & & & & & & & \\
\hline Eden 2006 & 1 & 42 & 30 & 558 & $11.5 \%$ & $0.43[0.06,3.23]$ & & \\
\hline Jaffe 2007 & 64 & 119 & 34 & 119 & $43.9 \%$ & $2.91[1.70,4.98]$ & & \\
\hline Menard 2008 & 7 & 46 & 34 & 594 & $11.6 \%$ & $2.96[1.23,7.10]$ & & \\
\hline $\begin{array}{l}\text { Yang } 2015 \\
\text { Subtotal }(95 \% \mathrm{CI})\end{array}$ & 13 & $\begin{array}{r}35 \\
242\end{array}$ & 4 & $\begin{array}{r}35 \\
1306\end{array}$ & $\begin{array}{r}7.0 \% \\
74.0 \%\end{array}$ & $\begin{array}{r}4.58[1.32,15.93] \\
2.69[1.79,4.03]\end{array}$ & & \\
\hline \multicolumn{9}{|c|}{$\begin{array}{l}\text { Heterogeneity: } C h i^{2}=4.00, d f=3(P=0.26) ; I^{2}=25 \% \\
\text { Test for overall effect: } Z=4.79(P<0.00001)\end{array}$} \\
\hline \multicolumn{9}{|l|}{ 1.4.2 Robotic } \\
\hline Hung 2014 & 4 & 16 & 20 & 184 & $6.7 \%$ & $2.73[0.80,9.29]$ & & \\
\hline Martin 2008 & 2 & 24 & 40 & 486 & $9.6 \%$ & $1.01[0.23,4.47]$ & & \\
\hline $\begin{array}{l}\text { Tugcu } 2015 \\
\text { Subtotal }(95 \% \mathrm{CI})\end{array}$ & 10 & $\begin{array}{l}25 \\
65\end{array}$ & 7 & $\begin{array}{r}36 \\
706\end{array}$ & $\begin{array}{r}9.6 \% \\
26.0 \%\end{array}$ & $\begin{array}{l}2.76[0.87,8.72] \\
2.11[1.04,4.25]\end{array}$ & & \\
\hline \multicolumn{9}{|c|}{$\begin{array}{l}\text { Heterogeneity: Chi } i^{2}=1.32, d f=2(P=0.52) ; I^{2}=0 \% \\
\text { Test for overall effect: } Z=2.07(P=0.04)\end{array}$} \\
\hline Total $(95 \% \mathrm{CI})$ & & 307 & & 2012 & $100.0 \%$ & $2.54[1.79,3.60]$ & & \\
\hline Total events & 101 & & 169 & & & & & \\
\hline $\begin{array}{l}\text { Heterogeneity: } \mathrm{Chi}^{2}= \\
\text { Test for overall effect }\end{array}$ & $\begin{array}{l}5.71, \mathrm{df} \\
Z=5.22\end{array}$ & $\begin{array}{l}6(P= \\
(P<0 . C\end{array}$ & $\begin{array}{l}0.46) ; 1^{2} \\
00001)\end{array}$ & $2=0 \%$ & & & 0.010 .1 & Favours [ \\
\hline
\end{tabular}

Figure 10. Forest plot of the effect of the previous TURP with surgical complication

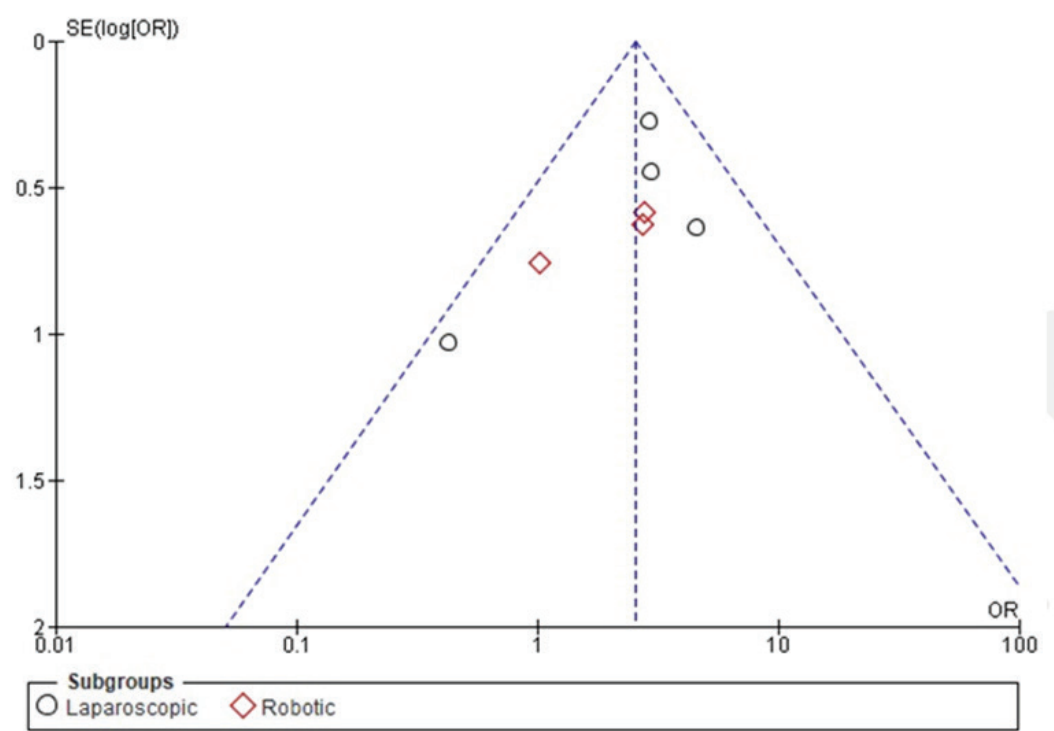

Figure 11. Funnel plot of the effect of the previous TURP with surgical complication

\section{DISCUSSION}

As mentioned before, RP is the gold standard in localized prostate cancer therapy and has become an elective treatment for primary and incidental localized prostatic cancers after the previous surgery for the obstructive benign disease $[3,5]$. The previous surgery such as TURP had incidentally detected occult adenocarcinoma prostate with the incidence ranging 1.4-5.2\%. However, since many factors can affect this condition, the incidence was varied around the world $[23,24]$.
From the Forest plot results, it is known that the TURP pre-RP action is not statistically significant because it passes the line of no effect $(\mathrm{O}=1.19,95 \% \mathrm{Cl}=0.93-1.53)$. However, when viewed from the perspectives of laparoscopic compared with robotic techniques, the robotics group obtain a significant result where the control patients who have TURP surgery before RP have a better ratio. Higher positive surgical margin rates in patients with previous TURP might be related to the surgeons who did the RP that tend to do a wider margin of resection. There's lack of evidence to support inflammatory adhesion preventing the negative surgical 
margin in patients without TURP history and studies regarding this data are scarce. In contrast with men without previous TURP, surgeons would perform RP with neurosparring techniques [26]. The results of this data processing are in line with previous meta-analysis studies conducted by Gacci et al. in 2013 where there are differences in patients who underwent previous TURP surgery [12].

In the patient with the history of TURP, a comparison of surgical, oncological, and functional outcomes after different techniques of radical prostatectomy has been reported by Mustafa et al. [8] The study compared two different groups of patients (robotic radical and open radical prostatectomy; 31 and 17 patients respectively) and evaluated biochemical recurrence as detectable prostate-specific antigen (PSA) serum level post-RP. The study found that no patient had detectable PSA level. The study of Mustafa et al. shows groups I and II had positive margins $(12.9 \%$ and $11.8 \%)$, incontinence ratios (70\% and $80.81 \%)$, and potential ratios $(68.2 \%$ and $46.1 \%)$, respectively. PSA values at the last follow-up were not detected except in 2 patients who had PSA values of 0.2 and $1 \mathrm{ng} / \mathrm{mL}$, respectively. 8 The diminished PSA level occurred mainly to prostate tissue mass reduction post-prostatectomy. This effect should be bigger than PSA decrease caused by anti-androgen administration.

Some authors considered prior TURP as a risk factor for anastomotic stricture, erectile dysfunction, and urinary incontinence although several studies have not demonstrated any increased morbidity or detrimental effects on the oncological or functional results $[9,10,18,21]$. The outcomes of robotic RP are comparable to those of open RP with acceptable oncological results and worst post-operative functional outcomes with respect to continence and erectile functions. There are different results from different series of laparoscopic and robotic-assisted RP (RARP) after TURP [8].

One the other hand, Colombo et al. [5] reported that open RP could be safely performed after previous TURP. Jaffe et al. [15] and Gupta et al. [21] reported worse surgical outcomes with high perioperative complications. Menard et al. [18] and Zugor et al. [22] reported that LRP and RARP resulted in worse perioperative outcomes and higher complication rates without compromising the oncological outcomes. Martin et al. [17] reported no higher complication rates and similar oncological outcomes after RARP. In the study of Eden et al. [11], LRP resulted in no difference in complication rates and comparable Positive Surgical Margin (PSM) and Biochemical Recurrences (BCR) with delay incontinence and no difference in erection rates. Performing robotic or open RP for prostate cancer in patients who had previous TURP is a technically demanding issue. The outcomes of robotic RP are com $\sim$ parable to those of open RP with acceptable oncological results [8]. Higher complication rates and longer operation duration might happen in post-TURP patients because the previous TURP causes the rigidity, thickness, fibrotic tissue formation of the bladder neck and the loss of elasticity in the urethra that increase the need for bladder neck reconstruction [20]. The patients should be informed about the po-tential intraoperative complications and worse post-op-erative functional outcomes with respect to continence and erectile functions.

The study of Wagenhoffer et al. [23] looked at the comparison between the results and complications of robotic-assisted prostatectomy (RALP) and endoscopic extraperitoneal radical prostatectomy (EERPE). A total of 100 patients underwent RALP procedures from August 2011 to October 2012 and 86 patients who approved the EERPE procedure from January 2008 to June 2011. The second group showed clinical characteristics similar to prostate volume, PSA, and D'Amico classification. The RALP surgery compared to EERPE surgery showed a shorter duration of surgery (183 vs. 157 minutes) and less blood loss (147 vs. $245 \mathrm{ml}$ ). Complications related to the assessment by Clavien-Dindo classification. In terms of complications, three patients in the RALP group and six patients in the EERPE group had high complexity. This study also showed a significant difference in the duration of surgery and catheter. The blood loss was statistically, but not clinically significant.

The study of Yang et al. [20] analyzed oncological, surgical, and functional outcomes in radical prostatectomy (LRP) laparoscopy in patients with TURP or without TURP. The prospective research from January 2002 to December 2012, conducted in 35 patients in the TURP group and 35 patients in the non-TURP group showed similar clinicopathological characteristics. Complications related to surgery and function in the group. In terms of complications, the TURP group compared to the group without TURP had a higher blood limit (231 vs. 139 $\mathrm{ml}$ ), longer duration of surgery (262 vs. 213 minutes), higher transfusion transfer $(8.6 \%$ vs. $0 \%)$, and higher rates of complication ( $37.1 \%$ vs. $11.4 \%$ ). The continence rates at one year after surgery were similar, but a lower continence rate was identified in the TURP group $142.9 \%$ vs. $68.6 \%$ ) at 3 months. Blood loss and higher blood transfusion rates in TURP group may be attributed to the extravasation of blood and fluid irrigation during TURP, which resulted in periprostatic fibrosis and obscured the proper planes between tissues $[2,5]$. Scarring and fibrosis of the previously resected bladder neck complicate healing at the anastomosis [20]. Some studies demonstrated that NVB preservation was technically feasible in approximately $33 \%$ to $56.5 \%$ of LRP patients after TURP $[11,18]$.

The quality of life may differ and vary individually regarding measuring instruments used by the researchers. However, several studies show consistent data that a higher positive surgical margin is associated with higher 
local recurrence rate, higher metastatic rate, and lower survival expectancy among patients with prostate cancer. Although this factor might not directly affect patient's quality of life, it certainly makes patients and their families spend more time to deal with the burden of their disease.

The learning curves for robotic surgery adoption may not be so steep since there are many similarities regarding both techniques. In addition, laparoscopic surgeries have been routinely performed by almost all urologists in Indonesia. The limiting factor of robotic surgery is the perception of stakeholders. It is undeniable that robotic instruments are often not affordable for most hospitals in developing countries and convincing the stakeholders might be the most challenging part of doing robotic surgeries. However, this issue falls beyond the scope of this review. Although evidence is still mounting, several experts have argued that robotic surgeries are considered superior to conventional laparoscopic surgeries. The robotic surgery is already recommended widely for prostate cancer throughout several International guidelines due to its superior operability and consistency regarding the result.

Several limitations such as lack of unpublished articles in literature search and limited experimental studies regarding this topic are identified as the study limitation. It is also been noted that most of the experimental studies' findings do not apply the same qualitative outcomes, thus not complying with the criteria set by this review. To time of writing, the authors are confident that all clinical trials regarding the topic have not been included due to the lack of publication since literature search has been done to almost all medical databases available. Hopefully, these might not be any limitation as more studies are published, more institutions will adopt robotic surgery technique.

\section{CONCLUSIONS}

The TURP history prolongs the intraoperative duration and increases the surgical complication in laparoscopic or robotic RP. Meanwhile, there is no effect of the TURP history on the positive surgical margin and a slight effect on biochemical recurrence. Thus, laparoscopic and robotic RPs are still recommended for localized prostate cancer with the history of TURP.

\section{DECLARATIONS}

\section{Competing of Interest}

The authors declare are no potential conflicts of interest.

\section{Acknowledgement}

The authors would like to express our gratitude to everyone that contributed to the making of this research article.

\section{REFERENCES}

1. Mottet $\mathrm{N}$, Bellmunt J, Briers E, Bolla $\mathrm{M}$, Bourke L, Cornford P, et al. EAU - ESTRO - ESUR - SIOG Guidelines on Prostate Cancer [Internet]. European Association of Urology; 2017. Available from: uroweb. org/wp-content/uploads/09-Prostate-Cancer_2017_ web.pdf

2. Ferlay J, Soerjomataram I, Dikshit R, Eser S, Mathers $C$, Rebelo $\mathrm{M}$, et al. Cancer incidence and mortality worldwide: sources, methods and major patterns in GLOBOCAN 2012. Int J Cancer. 2015;136(5).

3. Gacci M, Simonato A, Lanciotti M, Ennas M, Varca $\mathrm{V}$, Maffezzini $\mathrm{M}$, et al. The impact of prior TURP on radical prostatectomy surgical margins: a multicenter analysis. Urologia internationalis. 2013;91(1):62-8.

4. Burnett $A L$, Aus G, Canby-Hagino ED, Cookson MS, D'Amico AV, Dmochowski RR, et al. American Urological Association Prostate Cancer Guideline Update Panel Erectile function outcome reporting after clinically localized prostate cancer treatment. J Urol. 2007;178(2):597-601.

5. Colombo R, Naspro R, Salonia A, Montorsi F, Raber $M$, Suardi $N$, et al. Radical prostatectomy after previous prostate surgery: clinical and functional outcomes. J Urol. 2006;176(6 Pt 1):2459-63; discussion 63.

6. Gupta NP, Singh P, Nayyar R. Outcomes of robotassisted radical prostatectomy in men with previous transurethral resection of prostate. BJU international. 2011;108(9):1501-5.

7. Jaffe J, Cathelineau X, Barret E, Vallancien G, Prapotnich D, Rozet F. Surgical outcomes in men undergoing laparoscopic radical prostatectomy after a transurethral resection of the prostate. European Urology Supplements. 2007;6(2):253.

8. Mustafa M, Davis JW, Gorgel SN, Pisters L. Robotic or Open Radical Prostatectomy in Men with Previous Transurethral Resection of Prostate. Urology journal. 2017;14(1):2955-60.

9. Stolzenburg J-U, Ho KMT, Do $M$, Rabenalt $R$, Dorschner W, Truss MC. Impact of previous surgery on endoscopic extraperitoneal radical prostatectomy. Urology. 2005;65(2):325-31.

10. Bhayani SB, Pavlovich CP, Strup SE, Dahl DM, Landman J, Fabrizio MD, et al. Laparoscopic radical prostatectomy: a multi-institutional study of conversion to open surgery. Urology. 2004;63(1):99-102. 
11. Eden CG, Richards AJ, Ooi J, Moon DA, Laczko I. Previous bladder outlet surgery does not affect medium-term outcomes after laparoscopic radical prostatectomy. BJU Int. 2007;99(2):399-402.

12. Gacci M, Simonato A, Lanciotti M, Ennas M, Varca $\mathrm{V}$, Maffezzini $\mathrm{M}$, et al. The impact of prior TURP on radical prostatectomy surgical margins: a multicenter analysis. Urol Int. 2013;91(1):62-8.

13. Hampton L, Nelson RA, Satterthwaite R, Wilson T, Crocitto L. Patients with prior TURP undergoing robot-assisted laparoscopic radical prostatectomy have higher positive surgical margin rates. J Robot Surg. 2008;2(4):213-6.

14. Hung CF, Yang CK, Ou YC. Robotic assisted laparoscopic radical prostatectomy following transurethral resection of the prostate: perioperative, oncologic and functional outcomes. Prostate Int. 2014;2(2):82-9.

15. Jaffe J, Stakhovsky O, Cathelineau X, Barret E, Vallancien G, Rozet F. Surgical outcomes for men undergoing laparoscopic radical prostatectomy after transurethral resection of the prostate. J Urol. 2007;178(2):483-7; discussion 7.

16. Leewansangtong $S$, Taweemonkongsap $T$. Is laparoscopic radical prostatectomy after transurethral prostatectomy appropriated? J Med Assoc Thai. 2006;89(8):1146-9.

17. Martin AD, Desai PJ, Nunez RN, Martin GL, Andrews $P E$, Ferrigni $R G$, et al. Does a history of previous surgery or radiation to the prostate affect outcomes of robot-assisted radical prostatectomy? BJU Int. 2009;103(12):1696-8.

18. Menard J, de la Taille A, Hoznek A, Allory Y, Vordos D, Yiou R, et al. Laparoscopic Radical Prostatectomy After Transurethral Resection of the Prostate: Surgical and Functional Outcomes. Urology. 2008;72(3):593-7.
19. Tugcu V, Atar A, Sahin S, Kargi T, Gokhan Seker K, IlkerComez Y, et al. Robot-Assisted Radical Prostatectomy After Previous Prostate Surgery. JSLS. 2015;19(4).

20. Yang Y, Luo Y, Hou GL, Huang QX, Lu MH, Si-tu J, et al. Laparoscopic Radical Prostatectomy after Previous Transurethral Resection of the Prostate in Clinical T1a and T1b Prostate Cancer: A Matched-Pair Analysis. Urol J. 2015;12(3):2154-9.

21. Gupta NP, Singh P, Nayyar R. Outcomes of robotassisted radical prostatectomy in men with previous transurethral resection of prostate. BJU Int. 2011;108(9):1501-5.

22. Zugor V, Labanaris AP, Porres D, Witt JH. Surgical, oncologic, and short-term functional outcomes in patients undergoing robot-assisted prostatectomy after previous transurethral resection of the prostate. Journal of endourology. 2012;26(5):515-9.

23. Wagenhoffer R, Gruner M, Schymik J, Schachtner L, Neagoe L, Berg C, et al. Switching from Endoscopic Extraperitoneal Radical Prostatectomy to Robot-Assisted Laparoscopic Prostatectomy: Comparing Outcomes and Complications. Urol Int. 2015;95(4):380-5.

24. Varghese J, Kuruvilla PM, Mehta N, Rathore RS, Babu M, Bansal D, Pillai B, et al. Incidentally Detected Adenocarcinoma Prostate in Transurethral Resection of Prostate Specimen: a Hospital Based Study from India. Asian Pac J Cancer Prev. 17(4), 2255-58.

25. Otto B, Barbieri C, Lee R, Te AE, Kaplan SA, Robinson $B$, Chugtai B. Incidental Prostate Cancer in Transurethral Resection of the Prostate Specimens in the Modern Era. Advances in Urology, Adv Urol. 2014;2014:627290.

26. Do M, Haefner T, Liatsikos E, Kallidonis P, Hicks J, Dietel A, Horn L, et al. Endoscopic Extraperitoneal Radical Prostatectomy AFter previous Transurethral Resection of Prostate: Oncologic and Functional Outcomes of 100 Cases. Urology. 2010;75:1348-52. 